\title{
Nasogastric Tube Syndrome: The Unilateral Variant
}

\author{
Vikas Inder Nath Nehrua Hussein J asser AI Shammari a \\ Abdul Mohsen J afferb \\ a Al Adan Hospital, Kuwait, and b Al Sabah Hospital, Kuwait
}

\section{Key Words}

Nasogastric tube - Larynx · Posterior cricoarytenoid muscle

\begin{abstract}
Nasogastric tube syndrome is an uncommon but a potentially life-threatening complication of nasogastric intubation. It presents as an acute upper airway obstruction secondary to bilateral abductor vocal cord dysfunction resulting from postcricoid chondritis. However, a unilateral variant has also been reported and may herald the development of bilateral pathology. The purpose of this report is to highlight early warning signals of impending crisis. Clinical Presentation: A case of unilateral vocal cord involvement secondary to postcricoid chondritis resulting from nasogastric intubation is presented. An additional feature, not reported previously, is the presence of two inflammatory nodular swellings over the cricoid cartilage.
\end{abstract}

Copyright $@ 2003$ S. Karger AG, Basel

\section{Introduction}

The nasogastric tube syndrome is a rare entity described by Sofferman and Hubbell [1]. Up until January 2001 the literature contained 31 documented cases [2]. The syndrome comprises throat pain, presence of a naso- gastric tube and vocal cord abductor dysfunction. Although unilateral dysfunction has been reported in the past, classically the syndrome presents rather dramatically when vocal cord abductor dysfunction is bilateral and complete resulting in airway obstruction and necessitating a tracheostomy. There appears to be little correlation between the duration of nasogastric tube placement and the onset of the symptoms. The pathologic correlate of the clinical syndrome is an ulceration of the posterior surface of the cricoid region compromising the function of posterior cricoarytenoid muscle(s).

It is hypothesized that an early and adequate investigation of hoarseness and pharyngodynia in a patient on nasogastric tube feeding is critical to diagnosis and timely management of nasogastric tube syndrome. This policy should minimize the need for tracheostomy.

\section{Case Report}

A 60-year-old Kuwaiti man was admitted to Al Adan Hospital, State of Kuwait, on October 18, 2000. An insulin-dependent diabetic and hypertensive, convalescing from a mild residual hemiparesis on account of a previous thrombotic cerebrovascular accident, he suffered a second cerebrovascular accident and was hospitalised in an acute confusional state with a Glasgow Coma Scale of $8 / 15$. He was unable to support himself and was noted to have complete hemiplegia on the right side. A computerised tomographic scan of the head showed a left temporal infarct. He was nursed in an intensive care environment with ventilatory support via endotracheal intubation. A rigid nasogastric tube FG 16 was secured in place for feeding. Five days later the endotracheal tube was replaced with a tracheostomy.

\section{KARGER \\ Fax +41613061234 E-Mail karger@karger.ch www.karger.com

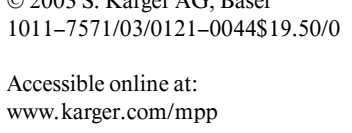

Dr. Vikas I. Nehru

Department of ENT

Al Adan Hospital

Ahmedi Region (Kuwait)

Tel. +965 3940600, ext.5651, Fax+965 5394237, E-Mail docvik9@hotmail.com 
His diabetes and hypertension were stabilized. However, he developed post CVA seizures, recurrent chest infections, catheterrelated infection and stress gastritis which were managed conservatively. In the first week of January 2001, he showed spontaneous eye opening and an effort to respond to verbal commands and showed further recovery of the neurological deficits over the following weeks. On March 8, 2001, an otolaryngology consultation was requested for removal of the tracheostomy tube. A flexible fiberoptic endoscopy revealed inhibited abductor movement of left true vocal cord and oedema of left arytenoid. In addition, two mucosa-covered nodular swellings were noted over the upper part of left half of posterior surface of the cricoid cartilage, measuring $8 \mathrm{~mm} \times 4 \mathrm{~mm}$ and $5 \mathrm{~mm}$ $\times 3 \mathrm{~mm}$, respectively (fig. 1). The nasogastric tube was abutting the medial of the two swellings. The right true cord was mobile and the glottic chink on deep inspiration appeared adequate. A further fiberoendoscopic examination of the hypopharynx and oesophagus using insufflation technique revealed few white striations on the posterior surface of the cricoid cartilage leading up to the nodular swellings and suggestive of scar tissue. The nasogastric tube was removed.

The subglottis was normal. There was a small suprastomal ledge of fibrovascular tissue that was later removed to facilitate a successful decannulation. Subsequently, the patient was able to eat and breathe normally.

Histopathological examination of the excision biopsy of the postcricoid swelling showed an inflammatory lesion with signs of healing. On his last follow-up, the patient had further improvement in the abductor function of left true vocal cord.

\section{Discussion}

Iglauer and Molt [3] first described the nasogastric tube syndrome in 1939 in a series of 12 patients. Holinger and Loeb [4] described a further 4 cases in 1946. A total of 31 cases have been reported to date with an age range of 4-77 years (mean 47.4 years) and duration of placement of the tube from 2 to 52 days (mean 24.6 days). Of these cases, $77 \%$ required tracheostomy as the syndrome presented with a dramatic airway compromise. Direct correlation did not seem to exist between duration of placement and onset of symptoms. Accurate data were available only for 14 cases reported since 1981, all of which exhibited postcricoid inflammation, with 10 having bilateral dysfunction and 4 with a unilateral dysfunction [2].

The nasogastric tube is one of the most commonly used devices in hospital patient care. Al Adan is a 560-bed hospital and in the last year this hospital purchased 4,160 nasogastric tubes.

Commonly reported complications of nasogastric tube are alar necrosis, epistaxis and acute otitis media. Oesophageal perforation has been documented as a result of nasogastric intubation [5]. Oesophageal stricture following nasogastric tube placement has been reported [6]. Even intracranial placement has been reported [7].

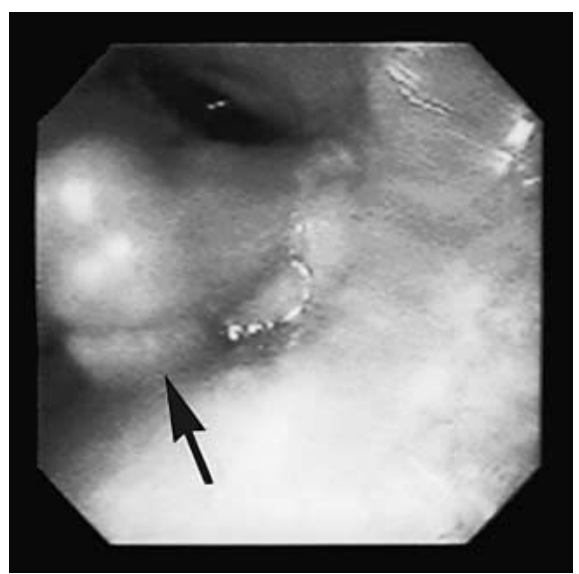

Fig. 1. Fiberoendoscopic photograph showing oedema of left arytenoid and two mucosa-covered swellings over upper part of the left half of posterior surface of the cricoid cartilage (see arrow).

The nasogastric tube syndrome, on the other hand, is an uncommon occurrence described by Sofferman and Hubbell [1]. The pathologic correlate of the clinical syndrome is an ulceration of posterior surface of the cricoid region with compromise of function of posterior cricoarytenoid muscle.

The proposed mechanisms include $[2,8]$ movement of the larynx during acts of coughing and swallowing against a vertically oriented semirigid tube; resting tonus in the cricopharyngeal sphincter pressing the tube against the posterior surface of the cricoid and compression of the tube between two rigid structures i.e. cricoid and anterior cervical spine as a consequence of gravity when the patient is supine.

A fourth possible mechanism would be a relationship between nasogastric tube syndrome and gastroesophageal reflux [9] due to decreased swallow reflex, decreased level of consciousness, supine position of the patient and presence of the tube across cardioesophageal junction.

The brunt of these events is borne by the posterior surface of the cricoid cartilage resulting in ulceration which may involve the mucosa, posterior cricoarytenoid muscle(s) and even cartilage in a varying spectrum of severity. Ischaemia, infection and necrosis may follow resulting in myopraxia of posterior cricoarytenoid muscle, which, when bilateral, may precipitate the classic nasogastric tube syndrome. Diabetes mellitus and immunocompromised states have been reported to encourage the development of nasogastric tube syndrome [2]. In a post-mortem study of 149 larynges of terminally ill patients, Wolff and 
Kesseler [10] found a 35\% incidence of postcricoid ulceration when tubes were in place for a minimum of $48 \mathrm{~h}$. In an animal model, Friedman et al. [11] found moderate to marked inflammation of the postcricoid region in $50 \%$ of the animals when a tube was placed in the midline for at least $24 \mathrm{~h}$.

In a study of 57 cases who had a nasogastric tube in place for a mean duration of 3.6 days, Sofferman and Hubbell [1] found $32 \%$ to have arytenoid oedema but no vocal cord dysfunction. This would indicate that there exists a clinical spectrum in which many less dramatic cases may escape diagnosis.

In patients on a tracheostomy for ventilatory support, the diagnosis may be delayed until an assessment is requested for decannulation of tracheostomy.

During an otolaryngologic evaluation, symptoms such as hoarseness or mild throat pain may be attributed to other causes if attention is focussed only on the endolarynx with a routine mirror or fiberoptic examination. The presence of nasogastric tube-induced injury can only be ruled out by either a rigid endoscopy or a fiberoptic endoscopy with a 'trumpet technique' using air insufflation for thorough examination of postcricoid space. In our patient, the diagnosis came to light only when endoscopic evaluation was made for decannulation of tracheostomy. The presence of mucosal scarring over the posterior surface of the cricoid region and chronic inflammatory reaction coupled with an abductor dysfunction would justify the diagnosis of nasogastric tube syndrome. The nodular swellings seen in our patient are not an essential component of the syndrome and appear to be end stage of resolving inflammation induced by prolonged nasogastric tube placement. We hypothesize that an early recognition of throat symptoms might avert the disaster of a full blown nasogastric tube syndrome and hence increase the significance of its unilateral variant. Spontaneous recovery of neurologic function of vocal cords has been reported [2] and follow-up our patient bears that out. Appropriate therapy should include removal of nasogastric tube, culture-specific antibiotics if a bacterial flora is present in the ulcer and treatment of gastroesophageal reflux with acid blockade. In selected patients, steroids may be of value to hasten recovery. Return of cord function relates to the extent of the process. Usually it takes 1-2 weeks but recovery may be delayed for up to 2 months in diabetics [6].

If a long-term requirement of nasogastric feeding is anticipated, a soft, small calibre, flexible nasogastric tube or a temporary percutaneous gastrostomy tube may provide better alternatives.

\section{Conclusion}

Considering the extensive use of nasogastric tubes in hospital practice, nasogastric tube syndrome deserves serious attention by all disciplines of medicine. It is suggested that an appreciation of warning signals may be utilized to prevent acute upper airway obstruction and a need of tracheostomy. For long-term placement, the use of rigid nasogastric tubes should be discouraged and either a soft flexible nasogastric tube or a temporary percutaneous gastrostomy should be considered.

\section{References}

1 Sofferman RA, Hubbell RN: Laryngeal complications of nasogastric tubes. Ann Otol Rhino Laryngol 1981;90:465-468.

2 Apostolakis LW, Funk GF, Urdaneta LF, Mc Culloch TM, Jeyapalan MM: The nasogastric tube syndrome: Two case reports and review of literature. Head Neck 2001;23:59-63.

3 Iglauer S, Molt WF: Severe injury to the larynx resulting from the indwelling duodenal tube. Ann Otol Rhinol Laryngol 1939;48:886-904.

4 Holinger PH, Loeb WJ: Feeding tube stenosis of the larynx. Surg Gynaecol Obstet 1946:83: 253-278.
5 Ahmed A, Aggarwal M, Watson E: Esophageal Perforation: A complication of nasogastric tube placement. Am J Emerg Med 1998;16:64-66.

6 Al-Sharhan A, Al-Sofferman H: Oesophageal stricture following nasogastric intubation. KMJ 2000;32:298-300.

7 Roberts JR, Hedges JR: Clinical Procedures in Emergency Medicine, et 3. Philadelphia, Saunders, 1998.

8 Sofferman RA, Haisch CE, Kirchner JA, Hardin NJ: The nasogastric tube syndrome. Laryngoscope 1990;100:962-968.
9 Dotson RG, Robinson RG, Pingleton SK: Gastroesophageal reflux with nasogastric tube: Effect of size. Am J Respir Crit Care Med 1994; 149:1659-1662.

10 Wolff AP, Kesseler S: Iatrogenic injury to the hypopharynx and cervical oesophagus. Ann Otol Rhinol Laryngol 1973;82:778-783.

11 Friedman M, Baim H, Shelton V, Stobnicki M, Chilis T, Ferrara T, Skolnik E: Laryngeal injuries secondary to nasogastric tubes. Ann Otol Laryngol Rhinol 1981;90:469-474. 